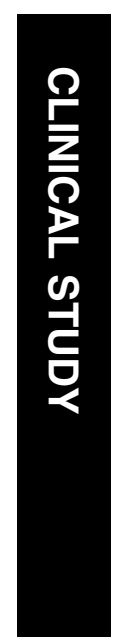

\section{The role of vascular endothelial growth factor in the progression of diabetic vascular complications}

RA Mahdy ${ }^{1}$, WM Nada ${ }^{1}$, KM Hadhoud ${ }^{2}$ and SA El-Tarhony ${ }^{3}$
'Department of

Ophthalmology, Faculty of Medicine, Zagazig University, Sharkia, Egypt

${ }^{2}$ Department of Internal Medicine, Faculty of Medicine, Zagazig University, Sharkia, Egypt

${ }^{3}$ Department of Medical Biochemistry, Faculty of Medicine, Zagazig University, Sharkia, Egypt

Correspondence: RA Rahman Mahdy, Department of Ophthalmology, Faculty of Medicine, Zagazig University, Sharkia 002, Egypt

Tel: + 0100089 782;

Fax: + 0020552384845 .

E-mail: redaelmahdy2005@ yahoo.com

Received: 27 January 2010 Accepted in revised form: 30 April 2010 Published online: 28 May 2010

\begin{abstract}
Purpose This study was planned to study the relationship between vascular endothelial growth factor (VEGF) as an angiogenic factor and different micro- and macrovascular complications in type II diabetic patients and look for a possible role of control on the serum level of VEGF.

Methods The study included 55 type II diabetic patients, 10 of them were not complicated with any of the vascular complications of type II diabetes mellitus (DM) (group 1), 21 patients had microvascular complication either retinopathy, nephropathy, or neuropathy (group 2), 14 patients had macrovascular complications either coronary artery disease or peripheral vascular disease (group 3), and 10 patients with mixed microand microvascular complications (group 4), as well as $\mathbf{1 5}$ healthy subjects served as control group. All subjects were subjected to complete clinical examination, including fundus examination, proper investigations with stress on electrocardiography, electromyography, nerve conduction velocity, Doppler study of the peripheral arteries, and laboratory investigations such as complete blood count, liver function test, serum creatinine, 24-h urinary albumin excretion, lipid profile, fasting and 2-h postprandial blood glucose, glycosylated haemoglobin $\left(\mathrm{HbA}_{1 \mathrm{c}}\right)$, and serum VEGF.

Results The study revealed that there was a highly significant increase in the serum VEGF in the diabetic patients compared with the control group. The $P$-value $(P<0.001)$ was detected and there was also a highly significant increase in the serum VEGF in the patients with different micro- and macrovascular diabetic complications
\end{abstract}

compared with uncomplicated diabetic group $(P<0.001)$. A highly significant increase in the serum VEGF in diabetic patients with proliferative diabetic retinopathy was detected compared with non-proliferative diabetic retinopathy (40.55 \pm 8.28 vs $20.3 \pm 2.45$, $P<0.001)$ and in diabetic nephropathic patients with macroalbuminuria compared with those with microalbuminuria $(36.14 \pm 6.99$ vs $19.42 \pm 2.44, P<0.001)$. The reduction of the serum VEGF in a group of diabetic patients with poor control when their diabetic state was corrected through 4 months follow-up was highly significant $(17.29 \pm 1.61$ before $v s$ $9.39 \pm 0.82$ after control $P<0.001$ ), as well as the reduction of the serum VEGF, which was observed in a group of patients with proliferative diabetic retinopathy (PDR) when proper pan retinal photocoagulation (PRP) was applied to their retinae with 4 months follow-up (40.55 \pm 8.28 before $v$ s $21.15 \pm 1.76$ after PRP, $P<0.001)$. On the other hand, the impact of some clinical and laboratory parameters of our diabetic patients on the serum VEGF revealed significant positive correlations between serum VEGF and age of the patients, duration of diabetes, systolic and diastolic blood pressure, body mass index, fasting and 2-h postprandial blood glucose, $\mathrm{HbA}_{1 c}$ serum creatinine, degree of albuminuria and total cholesterol, LDL, and platelet count.

Conclusion Serum VEGF was significantly increased in diabetic patients especially with micro- and macrovascular complications and the proper control of diabetes reduced the elevation of serum VEGF in uncontrolled diabetic patients, and in patients with PDR with proper PRP, indicating that VEGF is an 
angiogenic factor that reflects the degree of neovascularization in diabetic complications. Eye (2010) 24, 1576-1584; doi:10.1038/eye.2010.86; published online 28 May 2010

Keywords: VEGF; type II DM; vascular complications

\section{Introduction}

Cardiovascular complications are the leading cause of morbidity and mortality in patients with diabetes mellitus (DM), and up to $80 \%$ of deaths in patients with diabetes are closely associated with vascular disease affecting micro- or macrocirculation. ${ }^{1}$

During the past few years, rapid advancement has been made in our understanding of the mechanisms of the molecules involved in the pathogenesis of diabetic microvasculopathy. This is particularly true with regard to the role of the angiogenesis- and vasopermeabilityinducing molecule, vascular endothelial growth factor (VEGF). ${ }^{2}$

Angiogenesis is an essential biological process not only in emrbyogenesis but also in the progression of major diseases such as cancer, inflammation, and diabetes. VEGF family and its receptor system has been shown to be the fundamental regulator of cell signalling of angiogenesis. ${ }^{3}$

VEGFs are endogenously produced vascular cytokines, which result in angiogenesis, vasodilatation, and increased microvascular permeability in vivo. They are endothelial specific and result in mitosis, migration, stress fibre formation, and increased permeability of endothelial cells. $^{4}$

VEGF has been claimed to be a major positive regular of angiogenesis in diabetic retinopathy and atherosclerosis. $^{5}$

VEGF may be one of the predictors and risk factors for microalbuminuria and incipient diabetic nephropathy. ${ }^{6}$

VEGF is a major proangiogenic factor activating phosphati-dylinositol-3-kinase/Akt, and thus the cell survival, migration, and proliferation. Akt has been shown to phosphorylate endothelial nitric oxide synthase leading to a persistent calcium-independent enzyme activation and enhanced endothelial NO synthesis, and thereby influences the long-term regulation of vessel growth. The downstream effector pathways, by which NO mediates its effects, are less clear but may involve integrin-linked signal transduction process. ${ }^{7,8}$

VEGF is known also as vascular permeability factor on the basis of its ability to induce vascular leakage in the guinea pig skin. These early studies focused on protein extravasation. ${ }^{9}$ It has been shown that VEGF also induces an increase in hydraulic conductivity of isolated microvessels and that such an effect is mediated by increased calcium influx. ${ }^{10}$ Other studies have suggested that another important role of VEGF in the regulation of microvasclar permeability is the induction of a fenestrated phenotype in at least certain endothelial cell. ${ }^{11}$

VEGF induces the expression of the serine proteases urokinase- and tissue-type plasminogen activators (PAs) and also PA inhibitor 1 (PAI-1) in cultured bovine microvasuclar endothelial cells. ${ }^{12}$ Moreover, VEGF increases the expression of the metalloproteinase interstitial collagenase in human umbilical vein endothelial cells but not in dermal fibroblasts. ${ }^{13}$ The co-induction of PA and collagenase by VEGF is consistent with a pro-degradative environment that facilitates migration and sprouting of endothelial cells. It was proposed that PAI-1 provides a negative regulatory step that serves to balance the proteolytic process. ${ }^{14}$

One of the most studied microvascular complications in diabetes is proliferative retinopathy. ${ }^{15}$ In specimens of diabetic retinas, increased expression of VEGF and its receptors has been extensively demonstrated. ${ }^{16}$ Other growth factors, such as IGF-1 and its receptor, have been shown to collaborate with VEGF to increase retinal neovascularization. ${ }^{17}$ In addition, a study of diabetic patients who did not develop retinopathy showed that there was a correlation to impaired hypoxic induction of VEGF in these patients, again supporting the hypothesis that retinopathy involves hypoxic expression of VEGF as a fundamental aspect of its aetiology, ${ }^{1}$ and importantly, antagonists of VEGF and its receptors have been shown to reduce retinopathy in animal models. ${ }^{18}$ VEGF-induced permeability is also a likely contributor to the vascular leakage that greatly contributes to the morbidity of diabetic retinopathy. ${ }^{19-21}$

Thus, the aim of this work is to study the relationship between VEGF as the strongest known angiogenic factor and different micro- and macrovascular complications in diabetic patients and look for a possible role of glycaemic control on the serum level of VEGF.

\section{Materials and methods}

This study was carried out in the Departments of internal medicine, biochemistry, and ophthalmology, Faculty of medicine, Zagazig University.

The study was conducted on 70 subjects ( 55 patients with type II diabetes mellitus 'DM' and 15 healthy subjects).

They were divided into the following groups:

\section{Group 1}

It included 10 diabetic patients of uncomplicated type II DM, 6 males and 4 females. The duration of diabetes was between 2 and 7 years with a mean value \pm SD of 
$3.15 \pm 1.66$; their ages were between 37 and 65 years with a mean value \pm SD of $55.50 \pm 9.80$.

\section{Group 2}

It comprised 21 patients of type II DM with different microangiopathic complications, 11 males and 10 females. The duration of diabetes was 10-16 years with a mean value \pm SD of $12.72 \pm 3.23$; their ages range from 44 to 75 years with a mean value \pm SD of $58.84 \pm 8.32$.

\section{Group 3}

It comprised 14 diabetic patients of type II with different macroangiopathic complications, 7 males and 7 females. The duration of diabetes was between 3 and 10 years with a mean value \pm SD of $6.90 \pm 7.34$; their ages range from 49 to 73 years with a mean \pm SD of $60.2 \pm 2.3$.

\section{Group 4}

It comprised 10 type II diabetic patients with mixed micro- and macroangiopathic complications, 5 males and 5 females. The duration of diabetes was between 15 and 20 years with a mean value \pm SD of $17.14 \pm 4.23$; their ages range from 40 to 72 years with a mean value $\pm S D$ of $60.71 \pm 6.25$.

\section{Control group}

It included 15 healthy subjects of matched age and sex as diabetic patients (mean age $53.57 \pm 9.66$ ). A group of our patients $(n=9)$ with poor control were followed up for 4 months during which proper control was done and serum VEGF was studied before and after control in these patients. Another group of our diabetic patients $(n=6)$ with proliferative diabetic retinopathy (PDR) were followed up for 4 months during which pan retinal photocoagulation (PRP) was performed and serum VEGF was studied on them before and after PRP. Patients were randomly recruited from those attending the diabetes outpatient clinic of Zagazig University Hospitals.

After being informed on the purpose and procedures of the study, all subjects signed an informed consent form.

Type II DM was diagnosed according to the American Diabetes Association Guidelines for diagnosis and classification of DM. ${ }^{22}$ Diabetic vascular complications were divided into microvascular complications, including retinopathy, which was diagnosed according to the history and ophthalmoscopic examination by using ophthalmoscopy with fluorescein angiography after pupil dilatation; retinopathy was scored into non-proliferative and proliferative types. ${ }^{23}$ Neuropathy was diagnosed by history taking, full neurological examination, electromyography, and nerve conduction velocity studies. ${ }^{24}$ Nephropathy was diagnosed by the history, clinical examination, and the presence of microand macroalbuminuria in $24-\mathrm{h}$ albumin excretion in urine after exclusion of urinary tract infection by simple urine analysis. ${ }^{25}$

However, macrovascular complications include coronary heart disease, which was diagnosed according to history of characteristic chest pain and electrocardiographic performance. ${ }^{26}$ Peripheral vascular diseases were diagnosed based on history of limb ischaemic pain and intermittent claudications in addition to Doppler studies of the peripheral vascular system and an ankle brachial index of $\leqslant 0.8 .^{27}$

The following criteria were considered as exclusion criteria: smoking, hepatic diseases, thyroid diseases, rheumatoid arthritis, psoriasis, endometriosis, previous renal, retinal, neurological, cardiac, and peripheral arterial disorders.

All cases were subjected to the following:

- Thorough history taking, especially symptoms suggestive of micro- and macrovascular complications.

- Proper clinical examination with stress on:

- Body mass index (BMI) determination and waistcircumference.

- Blood pressure determination.

- Full neurological examination.

- Fundus examination.

- Proper investigations with stress on:

- Electrocardiography.

- Electromyography.

Nerve conduction velocity.

Doppler study of the peripheral arteries.

Laboratory investigations including:

- Complete blood count.

- Liver functions tests.

- Serum creatinine.

- 24-h urinary albumin excretion.

- Lipid profile (HDL, LDL, triglycerides, and total cholesterol).

- Fasting and 2-h postprandial blood glucose.

- Glycosylated haemoglobin $\left(\mathrm{HbA}_{1 \mathrm{c}}\right)$.

- Serum VEGF.

Using ACCUCYTE (Gentaur-Elisa, ACCUCYTE, Brussel, Belgium) human VEGF, which is a competitive enzyme immunoassay kit, the natural and recombinant forms of cytokine VEGF were measured.

\section{Statistical analysis}

Data were analysed by WINPEP statistical program (Genedrift.org). All data are expressed as means \pm SD. 
Analysis of trends was performed using linear regression. When comparing two groups, a Student's $t$-test was used, and to analyse data among groups of three or more, a one-way ANOVA was performed and secondary analysis was performed with the Student's $t$-test with Bonferroni correction.

\section{Results}

There was a highly significant increase in serum VEGF in different groups of patients compared with the control group $(P<0.001)$, and there was a highly significant increase in serum VEGF in groups 2, 3, and 4 when compared with group $1(P<0.001)$ (Table 1$)$.

There was no significant difference in age between group 1 and control group $(P>0.05)$; there was a significant increase in age between groups 2,3 , and 4 compared with control group $(P<0.05)$; there were no significant differences in BMI between groups 1 and 2 compared with control group $(P>0.05)$; there was a significant increase in BMI in group 3 compared with control group $(P<0.05)$; there was a highly significant decrease in $\mathrm{BMI}$ in group 4 compared with control group $(P<0.001)$; there was significant increase in systolic blood pressure (SBP) between group 1 compared with control group $(P<0.05)$, whereas there was a highly significant increase between groups 2, 3, and 4 compared with control group $(P<0.001)$; there was a highly significant

Table 1 VEGF of the studies groups

\begin{tabular}{lcc}
\hline Group & VEGF $(n g / m l)$ median (range) & Test of significance \\
\hline Control & $6.35(3.10-8.10)$ & 130.734 \\
& & $P<0.001$ \\
Group 1 & $16.25(10.70-18.90)^{* * *}$ & \\
Group 2 & $30.5(15.70-56.90)^{* * *}$ & \\
Group 3 & $59.30(36.70-71)^{* * *}$ & \\
Group 4 & $88.70(58.8-120)^{* * *}$ & \\
\hline
\end{tabular}

Significant in comparison with group $1(P<0.05)$. Significant in comparison with group $1(P<0.01)$. ***Significant in comparison with group $1(P<0.001)$. increase in diastolic blood pressure (DBP) in group 2, 3, and 4 compared with control group $(P<0.001)$; and there was no significant difference in DBP between group 1 and control group $(P=0.166)$ (Table 2$)$.

There were highly significant positive correlations between serum VEGF and age of the diabetic patients, duration of diabetes, SBP, and DBP $(P<0.001)$, and a significant positive correlation between VEGF and BMI of the diabetic cases. In addition, there were highly significant positive correlations between serum VEGF and $2 \mathrm{hPPBG}, \mathrm{HbA}_{1 \mathrm{c}}$, serum creatinine, albuminuria, platelet count, total cholesterol, and LDL of the studies cases $(P<0.001)$, and there was a significant positive correlation between serum VEGF and fasting blood glucose of the studied cases $(P<0.05)$ (Table 3$)$.

There were no significant correlations between serum VEGF and clinical and laboratory parameters in the control group, except for significant negative correlation with fasting blood glucose $(P=0.013)$ and significant positive correlation with SBP $(P=0.018)$ (Table 4$)$.

There was highly significant increase in serum VEGF in diabetic patients with PDR compared with NPDR $(P<0.001)$; in addition, there was a highly significant increase in serum VEGF in patients with macroalbuminuria compared with microalbuminuric patients $(P<0.001)$ (Table 5).

There was a highly significant reduction in the serum VEGF after glycaemic control for 4 months when compared with VEGF before glycaemic control in poorly controlled diabetic patients $(P<0.001)$ (Table 6$)$.

There was a highly significant reduction in the serum VEGF after PRP when compared with VEGF before PRP at the end of 4 months follow-up in patients with PDR $(P<0.001)$ (Table 7).

\section{Discussion}

VEGF is a potent mitogen for micro- and macrovascular endothelial cells derived from the arteries, veins, and lymphatics, but are devoid of consistent and appreciable mitogenic activity of other cell types. VEGF elicits a

Table 2 Clinical findings in the studies groups

\begin{tabular}{|c|c|c|c|c|}
\hline Group & $\begin{array}{l}\text { Age (years) } \\
\text { (means) }\end{array}$ & $\begin{array}{c}\text { Body mass index }\left(\mathrm{kg} / \mathrm{m}^{2}\right) \\
\text { (means) }\end{array}$ & $\begin{array}{c}\text { SBP }(\text { mmHg) median } \\
\text { (range) }\end{array}$ & $\begin{array}{c}D B P(m m H g) \\
\quad \text { (means) }\end{array}$ \\
\hline Control & $53.57 \pm 9.66$ & $26.48 \pm 4.31$ & $120(100-133)$ & $74.60 \pm 6.67$ \\
\hline Group 1 & $55.50 \pm 9.80$ & $28.4 \pm 4.54$ & $130^{* *}(110-140)$ & $77.25 \pm 6.32$ \\
\hline Group 2 & $58.84 \pm 8.32^{*}$ & $29.4 \pm 5.57$ & $145^{* * *}(115-175)$ & $88.26 \pm 9.81^{* * *}$ \\
\hline Group 3 & $61.90 \pm 7.34^{* * *}$ & $29.48 \pm 5.23^{* *}$ & $135^{* * *}(110-170)$ & $83.79 \pm 10.49^{* * *}$ \\
\hline Group 4 & $60.71 \pm 6.25^{* *}$ & $21.61 \pm 3.95^{* * *}$ & $155^{* * *}(120-180)$ & $89.29 \pm 8.98^{* * *}$ \\
\hline \multirow[t]{2}{*}{ Test of significance } & $\mathrm{F}=4.74$ & $\mathrm{~F}=3.851$ & $X^{2}=66.722$ & $\mathrm{~F}=15.39$ \\
\hline & $P=0.001$ & $P=0.005$ & $P<0.001$ & $P<0.001$ \\
\hline
\end{tabular}

*Significant in comparison with control group $(P<0.05)$.

**Significant in comparison with control group $(P<0.01)$.

***Significant in comparison with control group $(P<0.001)$. 
Table 3 Correlation between VEGF and some clinical variables in total diabetic patients $(n=50)$

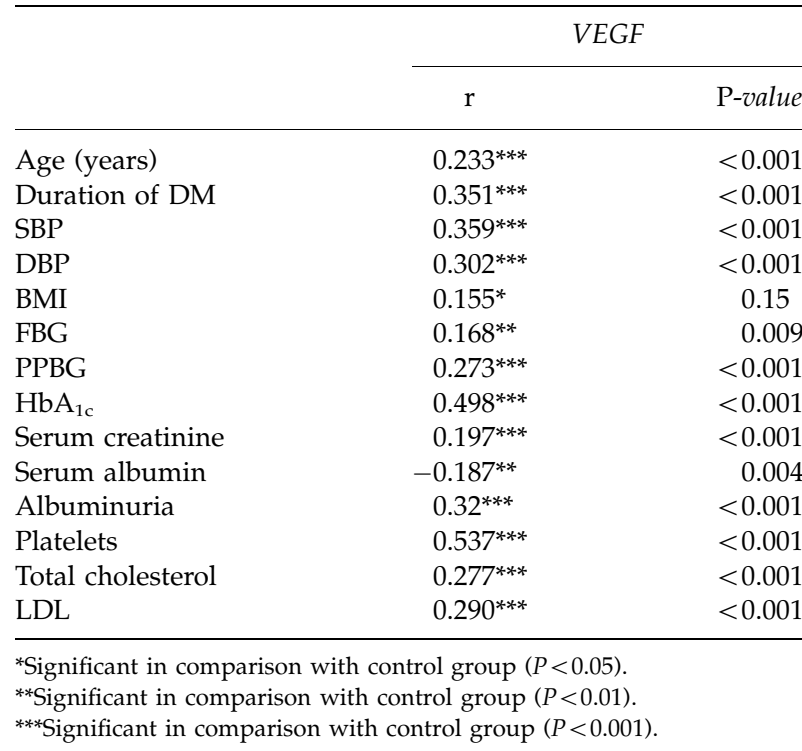

Table 4 Correlation between VEGF and some clinical and laboratory parameters in the control group

\begin{tabular}{lcc}
\hline & \multicolumn{2}{c}{ VEGF } \\
\cline { 2 - 3 } & $\mathrm{r}$ & P-value \\
\hline Age (years) & -0.104 & 0.585 \\
SBP & $0.428^{*}$ & 0.018 \\
DBP & -0.302 & 0.104 \\
BMI & 0.053 & 0.781 \\
FBG & $-0.449^{*}$ & 0.013 \\
PPBG & 0.29 & 0.877 \\
Serum creatinine & 0.090 & 0.635 \\
Serum albumin & -0.146 & 0.441 \\
Platelets & 0.125 & 0.510 \\
Total cholesterol & 0.114 & 0.549 \\
Triglycerides & 0.120 & 0.526 \\
HDL & -0.048 & 0.800 \\
LDL & 0.234 & 0.213 \\
\hline
\end{tabular}

*Significant in comparison with control group $(P<0.05)$.

Table 5 Comparison between VEGF in proliferative diabetic retinopathy (PDR) and non-proliferative diabetic retinopathy (NPDR), also between VEGF in microalbuminuria and macroalbuminuria in the diabetic patients with nephropathy

\begin{tabular}{lc}
\hline Stage & VEGF $(n g / m l)($ mean $\pm S D)$ \\
\hline Diabetic retinopathy & \\
$1 \quad$ NPDR $(n=6)$ & $20.31 \pm 2.45$ \\
2 PDR $(n=6)$ & $40.55 \pm 8.28$ \\
Test of significance & \\
Diabetic nephropathy & \\
$1 \quad$ Microalbuminuria $(n=3)$ & $19.42 \pm 2.44$ \\
2 Macroalbuminuria $(n=4)$ & $36.14 \pm 6.99$ \\
Test of significance & $t=6.189, P<0.001^{* * *}$ \\
\hline
\end{tabular}

***Significant in comparison between the two evaluated groups $(P>0.001)$.
Table 6 VEGF before and after glycaemic control $(n=9)$

\begin{tabular}{lc}
\hline & VEGF $($ mean $\pm S D)$ \\
\hline Before & $17.29 \pm 1.61$ \\
After & $9.39 \pm 0.82$ \\
Test of significance & $t=17.363, P<0.001 * * *$ \\
***Significant in comparison between the two evaluated groups $(P>0.001)$.
\end{tabular}

Table 7 VEGF before and after pan retinal photocoagulation in proliferative retinopathy $(n=6)$

\begin{tabular}{lc}
\hline & VEGF $($ mean $\pm S D)$ \\
\hline Before & $40.55 \pm 8.28$ \\
After & $21.15 \pm 1.76$ \\
Test of significance & $t=13.852, P<0.001^{* * *}$ \\
\hline$* * *$ Significant in comparison between the two evaluated groups $(P>0.001)$.
\end{tabular}

pronounced angiogenic response in a wide variety of in vivo models. ${ }^{28-30}$ There is also a strong evidence that VEGF is a survival factor for endothelial cells, both in vitro and in vivo. ${ }^{31}$

In this study, we tried to evaluate the relationship between VEGF and different micro- and macrovascular complications of diabetes in a group of type II diabetic patients. Our study showed a significant increase in the serum VEGF in our diabetic patients compared with non-diabetic control subjects (Table 1).

These findings were in agreement with the studies of March et $a l^{32}$ and Valabhji et $a l_{1}^{33}$ who observed that serum VEGF increased significantly in diabetic patients compared with non-diabetic healthy control subjects.

Malamitsi et $a l^{34}$ reported the same observation that serum VEGF increased significantly in diabetic patients compared with non-diabetic subjects, and added that diabetes is characterized by microangiopathy and increased angiogenic response in various organs. VEGF is a potent angiogenic factor and is involved in vascular endothelial cell growth.

Serum VEGF showed a significant increase in the diabetic patients of different micro- and macrovascular complications compared with the uncomplicated diabetic patients and the control non-diabetic subjects (Table 1).

These results indicate that VEGF may be implicated in the pathogenesis or aggravation of diabetic micro- and macrovascular complications.

The results were in agreement with the observations of Valabhji $e t a l^{33}$ and Wolf $e t a l^{35}$ who found that serum VEGF increased significantly in diabetic patients with microangiopathic complications compared with control cases as well as uncomplicated diabetic patients. Flyvbjerg $^{36}$ also reported that growth factors such as VEGF are implicated in the pathogenesis of diabetic microvascular complications such as retinopathy and nephropathy. 
Zhang et $a l^{37}$ also found that increased retinal vascular permeability is a common complication of diabetes and a major cause of vision loss in diabetic patients, and that downregulation of VEGF expression in the retina as by systemic and periocular deliveries of plasminogen kringle 5 (K5) can reduce retinal vascular permeability in rat models.

Serum VEGF concentrations were elevated significantly in our diabetic patients with neuropathy compared with uncomplicated diabetic patients and non-diabetic control cases (Table 1).

These results may point to the important role of VEGF in the pathogenesis of diabetic neuropathy; ischaemia and reduced $\mathrm{O}_{2}$ tension in the nerves of diabetic patients have always been observed and are thought to be the pathogenetic mechanisms of diabetic neuropathy. Again ischaemia and hypoxia are the most potent stimuli for VEGF secretion. VEGF by inducing neovascularization and accordingly enhancing blood and oxygen supply to the diabetic nerves may counteract the effects of ischaemia induced by hyperglycaemia and advanced glycation end products. Accordingly, enhanced VEGF secretion in patients with diabetic neuropathy may be considered as a protective mechanism against further ischaemia and hypoxia. ${ }^{38}$

Our diabetic patients with macrovascular complications had increased serum VEGF concentrations compared with uncomplicated diabetic and control non-diabetic subjects (Table 1). These results were in agreement with the study of Panutsopulos et $a l^{39}$ who found that serum VEGF was significantly increased in diabetic patients with coronary heart disease. They demonstrated that there was a statistically significant association of increased VEGF and FGF levels in peripheral monocytes in diabetic patients with stable angina and coronary heart disease.

Our results may be explained on the basis of the protective role of VEGF inducing neovascularization and enhancing collateral circulation in diabetic patients with macrovascular complications. In this regard, VEGF elevation will be beneficial and results from ischaemia induced by macrovascular complications. On the contrary, VEGF elevation may probably have a proatherogenic effect as the experimental in vivo study of Yonemitsu et al $^{40}$ showed that the introduction of human VEGF165 CDNA into rabbit carotid arteries induced prominent angiomatoid proliferation of endothelial cells and thickening of the intima due to fibromuscular hyperplasia. Accordingly, the proatherogenic role of VEGF will be harmful, and elevations of VEGF levels should precede the development of macrovascular complications. Whether VEGF is elevated before or after the occurrence of macrovascular complications, the exact role of VEGF in atherosclerotic lesions should be fully determined before advising VEGF treatment to enhance blood supply to the ischaemic myocardium or peripheral tissues in diabetic patients.

Makin et $a l^{41}$ observed that diabetic patients with peripheral artery disease had higher levels of plasma VEGF compared with controls, which suggested a link between the hypercoagulable state of peripheral, artery disease, and the process of angiogenesis.

Hochberg et $a l^{42}$ found that diabetic patients are at 10- to 20-fold increased risk for the development of critical limb ischaemia. VEGF is critical for the development of collateral blood vessels, which can effectively bypass peripheral arterial occlusions. Diabetics with critical limb ischaemia thus showed a significant rise in the plasma VEGF levels compared with uncomplicated and control subjects. In our study, obesity had a deleterious effect on both micro- and macrovascular complications of diabetes expressed as increased BMI in our diabetic patients with vascular complications when compared with the control healthy subjects (Table 2). These results were in agreement with Calle et $a l^{43}$ who observed that obesity predisposes to type II diabetes, and to hypertension, dyslipidaemia and ultimately atheroma which is considered one of the major causes of premature death in the obese.

Our study showed a significant increase in SBP and DBP in our diabetic patients compared with the healthy control subjects (Table 2). These results were in agreement with Slamler et $a l^{44}$ who reported that hypertension commonly coexists with type I and type II diabetes and is particularly associated with diabetic nephropathy. It is a major risk factor for both myocardial infarction and stroke.

Turner et $a l^{45}$ also found that $32 \%$ of type II diabetic males and $45 \%$ of females with no clinical evidence of atheromatous disease were hypertensive or were taking antihypertensive drugs. In male subjects who already had coronary artery disease, the prevalence of hypertension was even higher as $46 \%$. Tzeng et $a l^{46}$ and Valabhji et $a l^{33}$ also observed that SBP and DBP were higher in their diabetic patients, particularly, diabetic nephropathy when compared with non-diabetic subjects.

We have studied the impact of some clinical variables of our diabetic patients on the serum VEGF. We found significant positive correlations between serum VEGF and SBP and DBP, age of the patients, BMI, and duration of diabetes in our studied cases (Tables 3 and 4). These results may be due to the fact that complications of diabetes whether micro- or macrovascular are more prevalent in hypertensive obese patients with a long history of poor diabetic control.

Our findings were in agreement with Valabhji et al ${ }^{33}$ who observed that plasma VEGF concentrations were significantly correlated with blood pressure. 
Murata et $a l^{47}$ also observed a significant positive correlation between serum VEGF and the duration of diabetes in their studied cases of proliferative diabetic retinopathy.

We observed a significant positive correlation between serum VEGF and the metabolic control referred to by fasting and postprandial blood glucose and $\mathrm{HbA}_{1 \mathrm{c}}$ (Table 3). Again this may be related to the higher prevalence of diabetic micro- and macrovascular complications in poorly controlled diabetic patients. Our results were in agreement with the observations of Valabhji et $a l^{33}$ who reported that there was a significant correlation between serum VEGF and glycaemic control detected by $\mathrm{HbA}_{1 \mathrm{c}}$. Chiarelli et al ${ }^{48}$ found that glycaemic control influences VEGF serum levels and that serum VEGF significantly correlated with $\mathrm{HbA1c}$-patients with $\mathrm{HbA}_{1 \mathrm{c}}$ levels $>10 \%$ had significantly higher VEGF concentrations when compared with matched patients whose $\mathrm{HbA}_{1 \mathrm{c}}$ levels were $<10 \%$.

A group of our diabetic patients with poor control (with $\mathrm{HbA}_{1 \mathrm{c}}>10 \%$ ) were followed up for 4 months, during which proper control was performed (aiming to reduce $\mathrm{HbA}_{1 \mathrm{c}}$ to normal values). They showed a high significant reduction in serum VEGF concentrations compared with their levels before proper control (Table 6). These findings were in agreement with Valabhji et $a l^{33}$ who observed that serum VEGF reduced significantly with improved control for 2 years of prospective follow-up of a group of diabetic patients. Chiarelli et $a l^{48}$ also found a significant reduction in serum VEGF in poorly controlled diabetic patients with $\mathrm{HbA}_{1 \mathrm{c}}>10 \%$ when their $\mathrm{HbA}_{1 \mathrm{c}}$ were corrected below $7 \%$ through 2 years follow-up. The effects of proper glycaemic control may remove the stimulating effect of hyperglycaemia on VEGF secretion and may help to ameliorate or slowdown the progress of micro- and macrovascular complications with their resulting ischaemia, which is the strongest triggering factor for VEGF secretion.

Another group of our patients with proliferative diabetic retinopathy performed PRP and a prospective 4 months follow-up was done to study the effect of proper management of PDR by PRP on the serum VEGF. They showed a highly significant reduction in the serum VEGF compared with their values before PRP performance (Table 7). These observations agreed with the findings of Lip et al, ${ }^{49}$ Shinoda et al, ${ }^{50}$ and Endo et al, ${ }^{51}$ who detected a significant reduction in serum VEGF in a studied group of patients with PDR when performed effective PRP in 4 months follow-up.

These results may be explained by the beneficial effects of PRP on vision improvement, which remove the threat of impaired vision from the patients. In addition, PRP may cause ablation of many retinal cells capable of secreting VEGF such as retinal pigment epithelial ceils, pericytes, endothelial cells, Muller cells, and astrocytes. $^{37,51}$

\section{Conclusion}

The serum VEGF is significantly increased in diabetic patients especially with micro- and macrovascular complications and this elevation of VEGF was reduced in uncontrolled diabetic patients with proper glycaemic control, and in patients with PDR with proper PRP, indicating that VEGF is an angiogenic factor that reflects the degree of neovascularization in diabetic complications.

The content has not been published or submitted for publication elsewhere. The protocol for the research project has been approved by a suitably constituted ethics committee of the institution within which the study was undertaken and it conforms to the provisions of the Declaration of Helsinki in 1995 (as revised in Tokyo 2004).

The subject gave informed consent and the patient anonymity preserved.

\section{Summary}

What was known before

- Serum VEGF is significantly increased in diabetic patients especially with micro- and macrovascular complications.

What this study adds

- VEGF acts as a target for many new therapeutic modalities. Some of these modalities can aim to decrease angiogenesis and neovascularization as in proliferative diabetic retinopathy and nephropathy. Other therapeutic modalities can aim to induce angiogenesis and improve collateralization to increase peripheral circulation as in coronary artery disease and peripheral vascular disease.

\section{Conflict of interest}

The authors declare no conflict of interest.

\section{References}

1 Jean-Sebastein S, Bernard IL. Molecular basis of angiopathy in DM. Circ Res (2006); 98: 4-6.

2 Aiello LP, Wong JS. Role of vascular endothelial growth factor in diabetic vascular complications. Kidney Int Suppl 2000; 77: 113-119.

3 Shiboya M. Structure function of VEGF-I/VEGF receptor system involved in angiogenesis. Cell Struct Funct 2001; 26(1): 25-35.

4 Bates DO, Lodwick D, Williams B. Vascular endothelial growth factor microvascular permeability. Microcirculation 1999; 6(2): 83-96. 
5 Kimura I, Honda R, Kokai H, Kkabe M. Vascular endothelial growth factor promotes cell cycle transition from G0 to Gl phase in subcultured endothelial cells of diabetic rat thoracic aorta. Jpn J Pharmacol 2000; 83(1): 47-55.

6 Santilli F, Spagnoli A, Mohn A. Increased vascular endothelial growth factor serum concentrations may help to identify patients with onset of type 1 diabetes during childhood at risk for developing persistent microalbuminuria. J Clin Endocrinol Metab 2001; 86(8): 3871-3876.

7 Murohara T, Asahara T, Silver M, Bauters C. Nitric oxide synthase modulates angiogenesis in response to tissue ischemia. J Clin Invest 1998; 101: 2567-2578.

8 Gerber HP, McMurtrey A, Kowalski J, Minhong Y. Vascular endothelial growth factor regulates endothelial cell survival through the phosphatidylinopsitol 3'- kinase/Akt signal transduction pathway. J Biol Chem 1998; 273: 30336-30343.

9 Dvorak HF, Brown LF, Detmar M, Dvorak AM. Vascular permeability factor vascular endothelial growth factor, microvascular hyperpermeability, and angiogenesis. Am J Pathol 1995; 146: 1029-1039.

10 Bates DO, Curry FE. Vascular endothelial growth factor increases microvascular permeability via a $\mathrm{Ca} 2+$ dependent pathway. Am J Physiol Heart Circ Physiol 1997; 273: H687-H694.

11 Esser S, Wolburg K, Wolburg H, Breier G, Kurzchalia T, Risau W. Vascular endothelial growth factor induces endothelial fenestrations in vitro. J Cell Biol 1998; 140: 947-959.

12 Pepper MS, Ferrara N, Orci L, Montesano R. Potent synergism between vascular endothelial growth factor and basic fibroblast growth factor in the induction of angiogenesis in vitro. Biochem Biophys Res Comm 1992; 189: 824-831.

13 Unemori EN, Ferrara N, Bauer EA, Amento EP. Vascular endothelial growth factor induces intersitial collagenase expression in human endothelial cells. J Cell Physiol 1992; 153: 557-562.

14 Pepper MS, Montesano R. Proteolytic balance and capillary morphogenesis. Cell Differ Dev 1990; 32: 319-331.

15 Boultom M, Foreman D, Williams G, McLeod D. VEGF localization in diabetic retinopathy. $\mathrm{Br} J$ Ophthalmol 1998; 82(5): 561-568.

16 Ishida S, Shinoda K, Kawashima S, Oguchi Y, Okada Y, Ikeda E. Coexpression of VEGF receptors VEGF-R2 and neurophilin-1 in proliferative diabetic retinopathy. Invest Ophthalmol Vis Sei 2000; 41: 1649-1656.

17 Smith G, McLeod D, Foreman D, Boulton M. Immunolocalisation of the VEGF receptors FLT-1, KDR and FLT-4 in diabetic retinopathy. Br J Ophthalmol 1999; 83: 486-494.

18 Ozaki H, Seo MS, Ozaki K, Yamada H, Yamada E, Okamoto $\mathrm{N}$. Blockade of vascular endothelial cell growth factor receptor signaling is sufficient to completely prevent retinal neovascularization. Am J Pathol 2000; 156: 697-707.

19 Aiello LP, Bursell SE, Clermont A, Duth E, Ishii H. Vascular endothelial growth factor induced retinal permeability is mediated by protein kinase $C$ in vivo and suppressed by an orally effective beta-isoform-selective inhibitor. Diabetes 1997; 46: 1473-1480.

20 Baumgartner L, Pieczek A, Manor O, Blair R, Kearney M, Walsh K et al. Constitutive expression of ph VEGF 165 after intramuscular gene transfer promotes collateral vessel development in patients with critical limb ischemia Circulation 1998; 97: 1114-1123.

21 Isner JM, Losordo DW. Therapeutic angiogenesis for heart failure. Nat Med 1999; 5: 491-492.
22 Expert Committee of the Diagnosis of Classification of DM. Report of the expert committee of diagnosis and classification of DM. Diabetes Care 1997; 20: 1183-1197.

23 Mizutani M, Kern TS, Lorenzi M. Accelerated death of retinal microvascular cells in human and experimental diabetic retinopathy. J Clin Invest 1996; 97: 2883-2890.

24 Taguchi T, Brownlee M. The biochemical mechanisms of diabetic tissue damage. Textbook of Diabetes. 3rd edn., Vol. 2, Chap. 2001; 47: 4.

25 Senthil D, Coundhury GG, McLaurin C, Kasinath BS. Vascular endothelial growth factor induces protein synthesis in renal epithelial cells: a potential role in diabetic nephropathy. Kidney Int 2003; 64(2): 468-479.

26 Mittelmarke BM, Psaty BM, Fried LP, Borhani NO, Tracy RP, Rautaharju PM et al. Prevalence of cardiovascular disease among older adults: the cardiovascular health study. Am J Epidemiol 1993; 137: 311-317.

27 Newman AB, Sutton-Tyrrell K, Voget MT, Kuller LH. Morbidity and mortality in hypertensive adults with a low ankle arm blood pressure index. JAMA 1993; 270: 487-489.

28 Kakizawa $\mathrm{H}$, Itoh $\mathrm{M}$, Imamura $\mathrm{S}$. The relationship between glycaemic control and plasma vascular endothelial growth factor and endothelin-1 concentration in diabetic patients. Metabolism 2004; 53(5): 550-555.

29 Ferrara N, Davis-Smyth T. The biology of vascular endothelial growth factor. Endocr Rev 1997; 18: 4-25.

30 Leung DW, Cachianes G, Kuang WJ, Goeddel DV, Ferrara N. Vascular endothelial growth factor is a secreted angiogenic mitogen. Science 1989; 246: 1306-1309.

31 Benjamin LE, Golijanin D, Itin A, Pode D, Keshet E. Selective ablation of immature blood vessels in established human tumors followed vascular endothelial growth factor withdrawal. J Clin Invest 1999; 103: 159-165.

32 Marsh S, Nakhoul FM, Skorecki K, Rubin A, Miller BP. Hypoxic induction of vascular endothelial growth factor is markedly decreased in diabetic individuals who do not develop retinopathy. Diabetes Care 2000; 23: 1375-1380.

33 Valabhji O, Dhanjil S, Nicolades AN, Elkeles RS, Sharp P. Correlation between carotid artery dispensability and serum vascular endothelial growth factor concentrations in diabetic subjects and non diabetic subjects. Metabolism 2001; 50(7): 825-829.

34 Malamits F, Puchner A, Sarandakoo A, Tziotis A. Serum level of basic fibroblast growth factor and vascular endothelial growth factor in patients with diabetes mellitus. Red Res 1998; 44(6): 873-875.

35 Wolf G, Chen S, Ziyaden FN. From the periphery of the glomerular capillary wall toward the center of disease : podocyte injury comes of age in diabetic nephropathy. Diabetes 2005; 54(6): 1626-1634.

36 Flyvbjerg A. Growth factors and diabetic complications. Diabetes Med 1990; 7: 387-399.

37 Zhang SX, Sima J, Wang JJ, Shao C, Fant J, Ma JX. Systemic and periocular deliveries of plasminogen kringle 5 reduce vascular leakage in rat models of oxygen induced retinopathy and diabetes. Curr Eye Res 2005; 30(8): 681-689.

38 Murakami T, Arai M, Sunada Y, Nakamura M. VEGF 164 gene transfer by electroporation improves diabetic sensory neuropthy in mice. J Gene Med 2006; 8(6): 773-781.

39 Pantsopulos D, Zafiropoulos A, Krambovitis E. Peripheral monocytes from diabetic patients with coronary artry disease display increased bFGF and VEGF mRNA expression. J Tränst Med 2003; 1(1): 6-21. 
40 Yonemitsu Y, Kaneda Y, Morishita R, Kazunori N, Nakashima $\mathrm{Y}$, Sueishi K. Characterization of in vivo gene transfer into the arterial wall mediated by the Sendai virus (hemagglutinating virus of Japan) liposomes: an effective tool for the in vivo study of arterial diseases. Lab Invest 1996; 75: 313-323.

41 Makin AJ, Silverman SH, Lip GY. Vascular endothelial growth factor in patients with established peripheral artery disease: a link between angiogenesis and thrombogenesis? Clin Sci (Lond) 2003; 104(4): 397-404.

42 Hochberg I, Hoffman A, Levy AP. Regulation of VEGF in diabetic patients with critical limb ischemia. Ann Vasc Surg 2001; 15(3): 388-392.

43 Calle EE, Thun MJ, Petrelli JM, Rodriguez C, Health CW. Body mass index and mortality in a prospective cohort of US adults. N Engl J Med 1999; 341: 1097-1105.

44 Slamler J, Vaccaro O, Neaton JD, Wintworth D. Diabetes, other risk factors and 12 years cardiovascular mortality for men screened in the multiple risk factor intervention trial. Diabetes Care 1993; 16: 343-344.

45 Turner RC, Millns H, Neil HAW. Risk factors for coronary artery disease in non insulin dependent diabetes mellitus: United Kingdom Prospective Diabetes Study (UKPDS). BMJ 1998; 346: 823-828.
46 Tzeng TF, Hsiao PJ, Hsieh J. Association of nephropathy ad retinopathy, blood pressure, age in newly diagnosed type 2 diabetes mellitus. Kaohsiung J Med Sci 2001; 17(6): 294-301.

47 Murata T, Nakagawa K, Khalil A, Ishibashi T. The relation expression of vascular endothelial growth factor and breakdown of blood retinal barrier in diabetic retinas. Lab Invest 1996; 47: 819-825.

48 Chiarelli F, Santilli F, Mohn A. Role of growth factors in the development of diabetic complications. Horm Res 2000; 53(2): 53-67.

49 Lip PL, Belgore F, Blann AD. Plasma VEGF and soluble VEGF receptor FLI-1 in proliferative retinopathy: relationship to endothelial dysfunction after laser treatment. Invest Ophthalmol Vis Sci 2000; 41(8): 9.

50 Shinoda M, Ishida S, Kawashima S, Wakabayashi T, Uchita $\mathrm{M}$, Matsuzaki $\mathrm{T}$ et al. Clinical factors related to aqueous levels of vascular endothelial growth factor, hepatocyte growth factor in proliferative diabetic retinopathy. Curr Eye Res 2000; 21(2): 655-661.

51 Endo M, Yanagisawa K, Tsuchida K. Increased levels of vascular endothelial growth factor and advanced glycation end products in aqueous humor of patients with diabetic retinopathy. Horm Metabol Res 2001; 33(5): 317-322. 